\title{
ADUBAÇÃO DE ORQUÍDEAS EM SUBSTRATOS COM FIBRA DE COCO
}

\author{
Fertilization of orchids in substrates with coconut fiber
}

\author{
Tátila Lima do Amaral' ${ }^{1}$ Janie Mendes Jasmim², João Sebastião de Paula Araújo ${ }^{3}$, \\ José Tarcísio Lima Thiébaut ${ }^{4}$, Fábio Cunha Coelho ${ }^{5}$, Claudimar Barreto de Freitas ${ }^{6}$
}

\begin{abstract}
RESUMO
Objetivou-se, nesta pesquisa, avaliar a eficiência de substratos e doses de adubação sobre o crescimento e teores foliares de nutrientes de híbridos de orquídeas do gênero Phalaenopsis. O estudo constou de dois experimentos conduzidos em substrato com fibra de coco industrializada (Sub 1) e não industrializada (Sub 2), em mistura com casca de Pinus e brita zero (1:1:1 v/v/v), em delineamento de blocos casualizados. O primeiro experimento, em esquema de parcelas subdivididas no tempo (06 e 12 meses), com cinco repetições, avaliou o híbrido RJ 343, nos dois substratos, sob quatro doses de adubo mineral $\left(0 ; 0,9 ; 1,2 ; 1,5 \mathrm{~g} \mathrm{~L}^{-1}\right)$ e dois tratamentos adicionais [aplicação foliar de Aminon ${ }^{\circledR}\left(0,5 \mathrm{ml} \mathrm{L}^{-1}\right)$ na dose de $1,2 \mathrm{~g} \mathrm{~L}^{-1}$, no Sub $1 \mathrm{e}$ Sub 2]. O segundo avaliou o híbrido RJ 84-2, nos dois substratos, com as mesmas doses de adubo mineral e aplicação foliar de Aminon ${ }^{\circledast}\left(0\right.$ e $\left.0,5 \mathrm{ml} \mathrm{L}^{-1}\right)$, em esquema de parcelas subsubsubdivididas no tempo (6 e 12 meses), com três repetições. Avaliaram-se número de folhas, área foliar, área superficial de raízes, massa seca de folhas, raízes e total, e teores foliares de N, P e K. O Aminon ${ }^{\circledR}$ não teve efeito sobre o crescimento dos híbridos. O aumento da adubação promoveu aumento de crescimento, exceto de raízes, sendo o maior crescimento observado sob a dose de 1,5 $\mathrm{g} \mathrm{L}^{-1}$ de adubo mineral. O Sub 2 promoveu maior crescimento das plantas do híbrido RJ 343, enquanto o Sub 1 promoveu maior crescimento do híbrido RJ 84-2.
\end{abstract}

Termos para indexação: Phalaenopsis, fertilizantes, nutrição mineral.

\begin{abstract}
The research objective was to evaluate the efficiency of substrates and fertilization levels on the growth and leaf nutrient contents of orchid hybrids of the genus Phalaenopsis. The study consisted of two experiments in carried out with industrialized coconut fiber (Sub 1) and non-industrialized coconut fiber (Sub 2), in mixture with Pinus bark and grade zero gravel $(1: 1: 1 \mathrm{v} / \mathrm{v} / \mathrm{v})$ in randomized blocks. The first experiment in a split-plot scheme in time (6 and 12 months) with five replications, evaluated the hybrid RJ 343, in both substrates, under four levels of mineral fertilizer $\left(0 ; 0.9 ; 1.2 ; 1.5 \mathrm{~g} \mathrm{~L}^{-1}\right)$ and two additional treatments [leaf application of Aminon ${ }^{\circledR}\left(0.5 \mathrm{ml} \mathrm{L}^{-1}\right)$ at $1.2 \mathrm{~g} \mathrm{~L}^{-1}$, in Sub1 and Sub 2]. The second one evaluated the hybrid RJ 84-2, in both substrates, with the same mineral fertilizer levels and leaf application of Aminon ${ }^{\circledR}\left(0 \mathrm{e}^{0.5} \mathrm{ml} \mathrm{L}^{-1}\right)$, in a split-split-split plot scheme in time (6 and 12 months) with three replications. The number of leaves, leaf area, superficial root area, leaf, root and total dry weight, and N, P and K leaf contents were evaluated. Aminon ${ }^{\circledR}$ had no effect on the growth of the hybrids. Increase in fertilization led to increased growth, except for roots, with greater growth being observed at $1.5 \mathrm{~g} \mathrm{~L}^{-1}$ of mineral fertilizer. The Sub 2 caused greater growth of plants of the hybrid RJ 343, whereas the Sub 1 led to greater growth of the hybrid RJ 84-2.
\end{abstract}

Index terms: Phalaenopsis, fertilizers, mineral nutrition.

(Recebido em 26 de novembro de 2007 e aprovado em 9 de março de 2009)

\section{INTRODUÇÃO}

Em 2006, o Brasil exportou US\$ 29,6 milhões em flores e plantas ornamentais representando um crescimento de $14,8 \%$ em relação a 2005 , sendo a maior parte dos produtos exportados composta por mudas de plantas ornamentais incluindo orquídeas, no valor de US\$14,3 milhões (Kiyuna, 2007). No comércio exterior as orquídeas do gênero Phalaenopsis tiveram sua produção drasticamente aumentada nos últimos anos devido à evolução nas técnicas de produção e o interesse dos consumidores (Wang \& Lee, 1994; Griesbach, 1995).

A evolução da floricultura brasileira apresentou uma grande demanda na produção de mudas e passou a exigir estudos e pesquisas envolvendo desde o

${ }^{1}$ CCTA/UENF - Av. Alberto Lamego - 2000 - P4 Sala 116 - Campos dos Goytacazes, RJ - 28013-602 - tlamaral@yahoo.com.br ${ }^{2}$ Laboratório de Fitotecnia do CCTA/UENF- Campos dos Goytacazes, RJ

${ }^{3}$ Departamento de Fitotecnia do Instituto de Agronomia da UFRRJ - Seropédica, RJ

${ }^{4}$ LEAG/CCTA/UENF - Campos dos Goytacazes, RJ

${ }^{5}$ Laboratório de Fitotecnia do CCTA/UENF - Campos dos Goytacazes, RJ

${ }^{6} \mathrm{LFIT/CCTA/UENF}$ - Campos dos Goytacazes, RJ 
desenvolvimento de vasos e recipientes a substratos e técnicas de propagação (Salvador, 1995; Ferreira et al., 2007; Rocha et al., 2009). Assim, estudos têm sido realizados sobre o uso de substratos para a produção de orquídeas demonstrando que coxim e blocos de casca de coco, puros ou em misturas, propiciam condições de retenção de umidade e qualidade nutricional adequados para substituir o xaxim no cultivo de orquídeas epífitas (Demattê \& Demattê, 1996; Demattê \& Graziano, 2000). Da mesma forma, Assis et al. (2005) avaliaram o efeito de xaxim e de substratos à base de coco no cultivo de Dendrobium nobile, e concluíram que o coco desfibrado e a mistura de coco em cubos com pó de coco podem substituir o xaxim. Colombo et al. (2005) avaliando diferentes substratos, concluíram que o pó de coco e a fibra de coco apresentaram resultados semelhantes aos do xaxim na aclimatização de Cattleya. Yamakami et al. (2006) também avaliaram o efeito do xaxim e substratos alternativos, incluindo fibra de coco, e recomendam o uso de qualquer um deles no cultivo de Cattleya.

Com relação à adubação, Poole \& Seeley (1978) observaram maior crescimento e concentração de nutrientes em Cymbidium e Phalaenopsis com $100 \mathrm{mg} \mathrm{L}$ ${ }^{1}$ de N, 50 e $100 \mathrm{mg} \mathrm{L}^{-1}$ de Ke $25 \mathrm{mg} \mathrm{L}{ }^{-1}$ de $\mathrm{Mg}$; e com $50 \mathrm{mg}$ $\mathrm{L}^{-1}$ de N, P e K para Cattleya. Wang \& Gregg (1994) observaram que a dose de $1,0 \mathrm{~g} \mathrm{~L}^{-1}$ da formulação 20:20:20 causou aumento no número de flores e de inflorescências por planta, no número e tamanho das folhas e no diâmetro da haste de híbrido de Phalaenopsis. Por outro lado, Wang (1996) observou que híbridos de Phalaenopsis cultivados em Sphagnum apresentaram maior crescimento vegetativo, independentemente do fertilizante usado, na concentração de $200 \mathrm{mg} \mathrm{L}^{-1}$, mas as plantas adubadas com a formulação 10:30:20 apresentaram maior número de folhas que aquelas com a 20:20:20. Pridgeon (2001) afirma que diferentes proporções de adubos são recomendadas em função do substrato em que as plantas são cultivadas e que formulações ricas em fósforo, como a formulação 10-30-20, são indicadas para melhor florescimento.

A existência de um número restrito de referências sobre a combinação de adubação e substrato, aliada à diversidade de condições de cultivo e de espécies, enfatiza a necessidade de pesquisas sobre o cultivo de orquídeas nas condições brasileiras. Objetivou-se, neste trabalho avaliar o efeito de substratos compostos de fibra de coco e de doses de adubação mineral e de Aminon ${ }^{\circledR}$ sobre o crescimento e teores foliares de nutrientes em Phalaenopsis em área de produção comercial no estado do Rio de Janeiro.

\section{MATERIAL E MÉTODOS}

A pesquisa foi desenvolvida em orquidário comercial, em Maricá, RJ e constou de dois experimentos com híbridos de Phalaenopsis, cultivadas em dois substratos: fibra de coco industrializada (Sub 1) e não industrializada (Sub 2), em mistura com casca de Pinus e brita zero $(1: 1: 1 \mathrm{v} / \mathrm{v} / \mathrm{v})$, em vasos plásticos, transparentes contendo $0,8 \mathrm{~L}$ e adubadas semanalmente com adubo mineral nas doses $\left(0 ; 0,9 ; 1,2 ; 1,5 \mathrm{~g} \mathrm{~L}^{-1}\right)$. As partículas das fibras apresentavam: fibra não industrializada $-3 \mathrm{~cm}$ de comprimento e $1 \mathrm{~cm}$ de largura, $4,71 \mathrm{~g} \mathrm{~kg}^{-1}$, de $\mathrm{N}, 1,04 \mathrm{~g} \mathrm{~kg}^{-1}$ de $\mathrm{P}, 9,00 \mathrm{~g} \mathrm{~kg}^{-1}$ de $\mathrm{K}$ e 2,0 $\mathrm{g} \mathrm{kg}^{-1}$ de $\mathrm{Na}$; - fibra industrializada $-6 \mathrm{~cm}$ de comprimento e $2 \mathrm{~cm}$ de largura, $3,22 \mathrm{~g} \mathrm{~kg}^{-1}$ de N, 0,23 de P g kg-1 , 6,0 $\mathrm{g} \mathrm{kg}^{-1}$ de K e 0,5 $\mathrm{g} \mathrm{kg}^{-1}$ de Na.

No primeiro experimento foi estudado o híbrido RJ 343 (Phalaenopsis Portobello x Phalaenopsis Malibu Bistro), em esquema de parcela subdividida no tempo (seis e 12 meses), em delineamento em blocos casualizados com cinco repetições. Os tratamentos do fatorial completo foram dois substratos e quatro doses de adubo mineral, além de dois tratamentos adicionais com aplicação semanal do fertilizante foliar Aminon ${ }^{\circledR}\left(0,5 \mathrm{ml} \mathrm{L}^{-1}\right)$, nos dois substratos na dose de $1,2 \mathrm{~g} \mathrm{~L}^{-1}$, totalizando 10 tratamentos.

No segundo experimento foi estudado o híbrido RJ 84-2 [Phalaenopsis (Taisuco Adian x Taisuco Kochdian) x self] em esquema de parcela subsubsubdividida no tempo (seis e 12 meses), em delineamento em blocos casualizados com três repetições. O fatorial foi composto da combinação dos dois substratos (Sub 1 e Sub 2), quatro doses de adubo mineral e com e sem a aplicação semanal do Aminon ${ }^{\circledR}(0,5$ $\left.\mathrm{ml} \mathrm{L}^{-1}\right)$.

As formulações do adubo mineral Peters ${ }^{\circledR}$ utilizadas durante o período vegetativo das plantas, setembro a fevereiro, foram NPK (28-14-14) por três semanas seguidas e (15-30-15) na quarta semana. Durante o período que antecede o florescimento, de março a agosto, foi aplicada a formulação NPK (15-30-15) durante três semanas seguidas e (28-14-14) na quarta semana. O fertilizante organomineral foliar Aminon ${ }^{\circledR}$ é composto $11 \%$ de nitrogênio, $1 \%$ de óxido de potássio e $25 \%$ matéria orgânica.

Nos dois experimentos, foram realizadas avaliações aos seis e 12 meses, retirando-se uma planta, ao acaso, para cada época de avaliação. Avaliou-se o número de folhas, a área foliar (medidor de bancada Li -3000, Li-COR Inc.), área superficial de raízes (Rossielo et al., 1995), massa seca de folhas, raízes e total, e teores foliares de N, P e K. As folhas foram secas e em estufa de circulação de ar forçada, a $70^{\circ} \mathrm{C}$, por $48 \mathrm{~h}$, para determinação da massa seca 
e, em seguida, moídas para determinação dos teores de NPK (Jones et al., 1991; Malavolta et al., 1997). O N foi determinado pelo método de Nessler (Jackson, 1965); o P segundo o método de Braga \& Defelipo (1974) e o K foi determinado foi espectrofotometria de absorção.

Os resultados foram submetidos à análise de variância, utilizando-se o software estatístico "SAEG" (Euclides, 1983). Foi analisado o contraste entre Sub 1 e Sub 2 e entre as épocas 6 e 12 meses. As comparações de médias foram efetuadas utilizando-se o teste $\mathrm{F}$, a $5 \%$ de significância. A análise de regressão com identidade modelo foi usada para as doses de adubação.

\section{RESULTADOS E DISCUSSÃO}

Híbrido RJ 343: Houve efeito significativo isolado da adubação sobre todas as variáveis analisadas. Mesmo não havendo interação entre os efeitos do substrato e da adubação, nem interação entre adubação e época, exceto para $\mathrm{N}$ e $\mathrm{K}$, houve interesse de se analisar as variáveis em conjunto.

Observou-se maior área e massa seca foliar nas plantas cultivadas no Sub 2, indicando que alguma característica da fibra de coco não industrializada promoveu maior expansão e acúmulo de massa seca das folhas, possivelmente a maior retenção de umidade em virtude do menor tamanho (Tabela 1). Por outro lado, o teor foliar de $\mathrm{N}$ foi maior em plantas cultivadas no Sub 1, podendo estar relacionado à menor massa seca das folhas (Tabela 1). Para as demais variáveis analisadas não houve diferença significativa.

Assis et al. (2005) também observaram que plantas de Dendrobium nobile Lindl, em pó de coco ou coco desfibrado, apresentaram melhor crescimento que aquelas cultivadas em cubos de coco devido à maior retenção de umidade daqueles materiais. Os mesmos autores observaram que a mistura de cubos com pó de coco favoreceu mais às plantas por combinar, ao mesmo tempo, as características de retenção de umidade e de aeração melhorando as condições físicas dos mesmos.

As doses de adubação aplicadas promoveram aumento linear no número de folhas, área foliar, massa seca das folhas e massa seca total, com maiores valores na maior dose de adubação aplicada $1,5 \mathrm{~g} \mathrm{~L}^{-1}$ (Figura 1a, 1b, 1c e 1d), mas houve redução na área superficial de raízes e massa seca das raízes (Figura 1e e 1f).

Plantas cultivadas no Sub 2 apresentaram maior área foliar e massa seca das folhas, com maior incremento de massa seca das folhas aos 12 meses de avaliação (Figura $1 \mathrm{~b}$ e $1 \mathrm{c})$.

A adubação causou aumento linear nos teores foliares de $\mathrm{N}$ independentemente do substrato, com interação adubação e época de avaliação. Os maiores teores de $\mathrm{N}$ nas folhas foram observados com a dose $1,5 \mathrm{~g}$ $\mathrm{L}^{-1}$, independentemente da época. Plantas cultivadas no Sub 1 apresentaram maiores teores de $\mathrm{N}$ nas folhas, possivelmente por terem menor crescimento em relação àquelas cultivadas no Sub 2 (Tabela 1 e Figura 2a). Os teores de $\mathrm{P}$ tiveram um aumento linear com o aumento da adubação, com maiores valores aos 12 meses de cultivo (Figura 2b). Houve decréscimo dos teores de $\mathrm{K}$ à medida que se aumentou a adubação, e houve interação adubação e época de avaliação, com maiores valores aos seis meses de cultivo sem adubação; aos 12 meses, houve aumento linear dos teores em função do aumento da adubação, embora esses tenham sido inferiores aos observados aos seis meses (Figura 2c).

Os valores observados para os teores foliares de $\mathrm{N}$ das plantas sob as doses $0,0,9$ e 1,2 $\mathrm{g} \mathrm{L}^{-1}$ de adubo mineral estão abaixo da faixa considerada adequada por Jones et al. (1991) (20-35 $\mathrm{g} \mathrm{kg}^{-1}$ de N, 2-7 $\mathrm{g} \mathrm{kg}^{-1}$ de P e 40-60 $\mathrm{g} \mathrm{kg}^{-1}$ de $\mathrm{K})$, enquanto aqueles da dose $1,5 \mathrm{~g} \mathrm{~L}^{-1}$ estão dentro da faixa adequada, bem como os teores de $\mathrm{P}$ de todos os tratamentos. Os teores de $\mathrm{K}$ das plantas de todos os tratamentos estão acima da faixa adequada. Entretanto,

Tabela 1 - Número de folhas (NF), área foliar (AF), área superficial de raízes (AR), massa seca das folhas (MSF), massa seca das raízes (MSR), massa seca total (MST) e teores foliares de nitrogênio (N), fósforo (P) e potássio (K) na massa seca das folhas de plantas Phalaenopsis RJ 343 cultivadas em substratos com fibra de coco industrializada (Sub 1) e com fibra de coco não industrializada (Sub 2).

\begin{tabular}{clcccccccc}
\hline Substrato & NF & $\begin{array}{c}\text { AF } \\
\left(\mathrm{cm}^{2}\right)\end{array}$ & $\begin{array}{c}\text { ASR } \\
\left(\mathrm{cm}^{2}\right)\end{array}$ & $\begin{array}{c}\text { MSF } \\
(\mathrm{g})\end{array}$ & $\begin{array}{c}\text { MSR } \\
(\mathrm{g})\end{array}$ & $\begin{array}{c}\text { MST } \\
(\mathrm{g})\end{array}$ & $\begin{array}{c}\mathrm{N} \\
\left(\mathrm{g} \mathrm{Kg}^{-1}\right)\end{array}$ & $\begin{array}{c}\mathrm{P} \\
\left(\mathrm{g} \mathrm{Kg}^{-1}\right)\end{array}$ & $\begin{array}{c}\mathrm{K} \\
\left(\mathrm{g} \mathrm{Kg}^{-1}\right)\end{array}$ \\
\hline Sub 1 & $4,41 \mathrm{a}^{*}$ & $106,66 \mathrm{~b}$ & $42,48 \mathrm{a}$ & $0,86 \mathrm{~b}$ & $0,96 \mathrm{a}$ & $1,94 \mathrm{a}$ & $17,43 \mathrm{a}$ & $3,84 \mathrm{a}$ & $82,08 \mathrm{a}$ \\
Sub 2 & $4,38 \mathrm{a}$ & $128,71 \mathrm{a}$ & $50,36 \mathrm{a}$ & $1,05 \mathrm{a}$ & $1,07 \mathrm{a}$ & $2,20 \mathrm{a}$ & $16,73 \mathrm{~b}$ & $3,70 \mathrm{a}$ & $79,65 \mathrm{a}$ \\
\hline
\end{tabular}

*Médias seguidas da mesma letra não diferem entre si pelo teste de $\mathrm{F}$, ao nível de $5 \%$ de probabilidade: as letras comparam médias de substratos. 

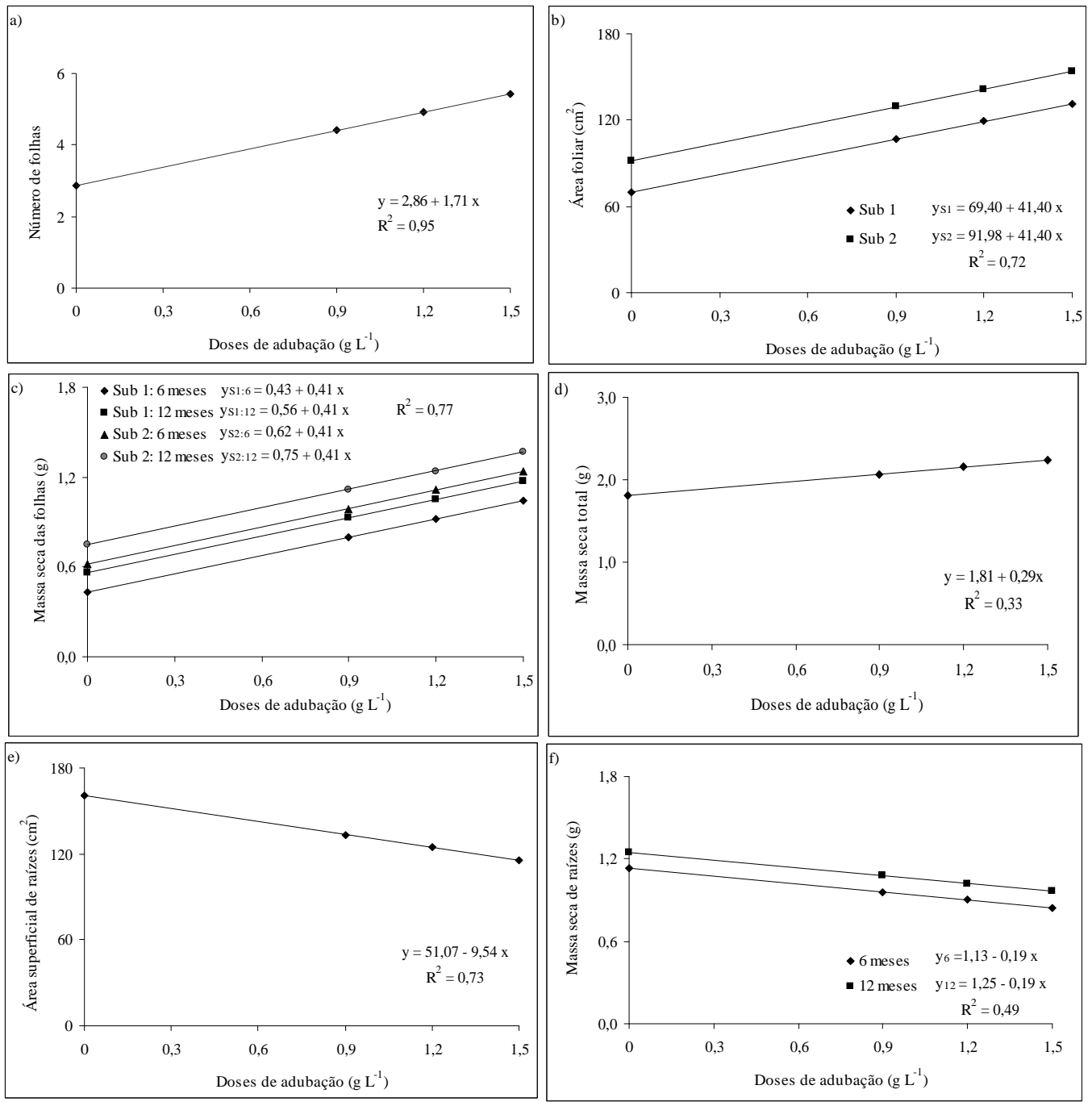

Figura 1 - Plantas de Phalaenopsis RJ 343 cultivadas em substrato com fibra de coco industrializada (Sub1) e não industrializada (Sub2) sob diferentes doses de adubação, aos seis e 12 meses de cultivo: a) número de folhas, b) área foliar, c) massa seca das folhas, d) massa seca total, e) área superficial de raízes e f) massa seca de raízes.

Moreno et al. (2000) relatam teores foliares de $\mathrm{N}$ semelhantes aos aqui observados e os consideram adequados, enquanto os teores de P são inferiores e os de $\mathrm{K}$ superiores aos encontrados pelo autor.

Foi observado efeito de época sobre a massa seca das folhas, massa seca das raízes e teor foliar de fósforo (Tabela 2), com maiores valores aos 12 meses.

No contraste entre a média dos tratamentos adicionais e o fatorial completo, as plantas adubadas com Aminon ${ }^{\circledR}$ apresentaram maior teor foliar de nitrogênio (19,91 e $16,78 \mathrm{~g} \mathrm{Kg}-1$ de N, respectivamente com e sem Aminon ${ }^{\circledR}$ ). Isso pode ser decorrente do fato do Aminon ${ }^{\circledR}$ ser composto de $11 \%$ de nitrogênio, dessa forma as plantas adubadas com esse fertilizante foliar receberam um complemento de nitrogênio. Apesar das plantas adubadas com Aminon ${ }^{\circledR}$ terem apresentado maior teor de $\mathrm{N}$, os teores observados para $\mathrm{N}$ estão abaixo daqueles descritos na literatura (Jones et al., 1991). Não houve efeito sobre as demais características.

No contraste entre as médias dos tratamentos adicionais, plantas cultivadas no Sub 1 apresentaram maiores teores foliares de $\mathrm{P}$ e $\mathrm{K}$ que aquelas cultivadas em substrato Sub 2 (4,43 e 3,62 $\mathrm{g} \mathrm{Kg}^{-1}$ de P e 91,38 e 80,09 $\mathrm{g} \mathrm{Kg}^{-1}$ de K, respectivamente Sub 1 e Sub 2). 
$\mathrm{Na}$ análise do contraste entre os tratamentos adicionais e o fatorial completo, o teor foliar de $\mathrm{N}$ das plantas cultivadas no Sub $1\left(21,12 \mathrm{~g} \mathrm{~kg}^{-1}\right)$ foi maior que aquele das plantas no Sub $2\left(17,15 \mathrm{~g} \mathrm{~kg}^{-1}\right)$ aos seis meses, mas aos 12 meses o inverso foi observado $\left(19,64\right.$ e $21,72 \mathrm{~g} \mathrm{~kg}^{-1}$ de $\mathrm{N}$ foliar das plantas no Sub 1 e Sub 2, respectivamente). O teor foliar de K das plantas cultivadas no Sub 1 foi maior que o das plantas no Sub 2 aos seis $\left(87,00\right.$ e $85,90 \mathrm{~g} \mathrm{~kg}^{-1}$, respectivamente Sub 1 e Sub 2) e aos 12 meses $(95,76$ e $74,28 \mathrm{~g} \mathrm{~kg}^{-1}$ respectivamente Sub 1 e Sub 2).

Híbrido RJ 84-2: A interação tripla de adubação, substrato e época não foi significativa para nenhuma das variáveis aleatórias analisadas, mas houve interação do substrato e adubação nos teores foliares de $\mathrm{P}$ e uma interação de adubação e época nos teores foliares de $\mathrm{N}$.

As plantas cultivadas no Sub 1 apresentaram maior área foliar, área superficial de raízes, massa seca das folhas, massa seca das raízes e massa seca total (Tabela 3). Nas demais variáveis analisadas não houve diferença significativa. Os teores foliares $\mathrm{N}$ e K não diferiram nas plantas cultivadas em ambos os substratos (Tabela 3), embora os teores de $\mathrm{K}$ encontrados na fibra não industrializada que compõem o Sub 2 sejam mais altos (6 e $9 \mathrm{~g} \mathrm{~kg}^{-1}$ de $\mathrm{K}$, respectivamente nos Sub1 e Sub 2) Os resultados indicam que alguma característica da fibra do Sub 2 restringiu o crescimento das folhas e raízes, com menor acúmulo de massa seca total nas plantas de Phalaenopsis RJ 84-2 (Tabela 3). Isso poderia indicar a sensibilidade desse híbrido ao teor de $\mathrm{Na}$ da fibra do Sub 2 ( 2 e $0,5 \mathrm{~g} \mathrm{~kg}^{-1}$ de Na, no Sub 1 e Sub 2, respectivamente), o que não foi observado para o híbrido RJ 343.

A aplicação foliar de Aminon ${ }^{\circledR}$ só foi significativa para o teor foliar de $\mathrm{P}$, com maior teor encontrado nas plantas que não receberam Aminon ${ }^{\circledR}$ (3,98 e 4,31 $\mathrm{g} \mathrm{Kg}^{-1}$ de $\mathrm{P}$, respectivamente com e sem Aminon $\left.{ }^{\circledR}\right)$.

As doses de adubação aplicadas promoveram aumento linear sobre número de folhas, área foliar, massa seca das folhas (Figura 3a, 3b e 3c), teores foliares de N, P e K (Figura 4a, 4b e 4c); com maiores valores observados na maior dose de adubação aplicada $1,5 \mathrm{~g} \mathrm{~L}^{-1}$. Somente

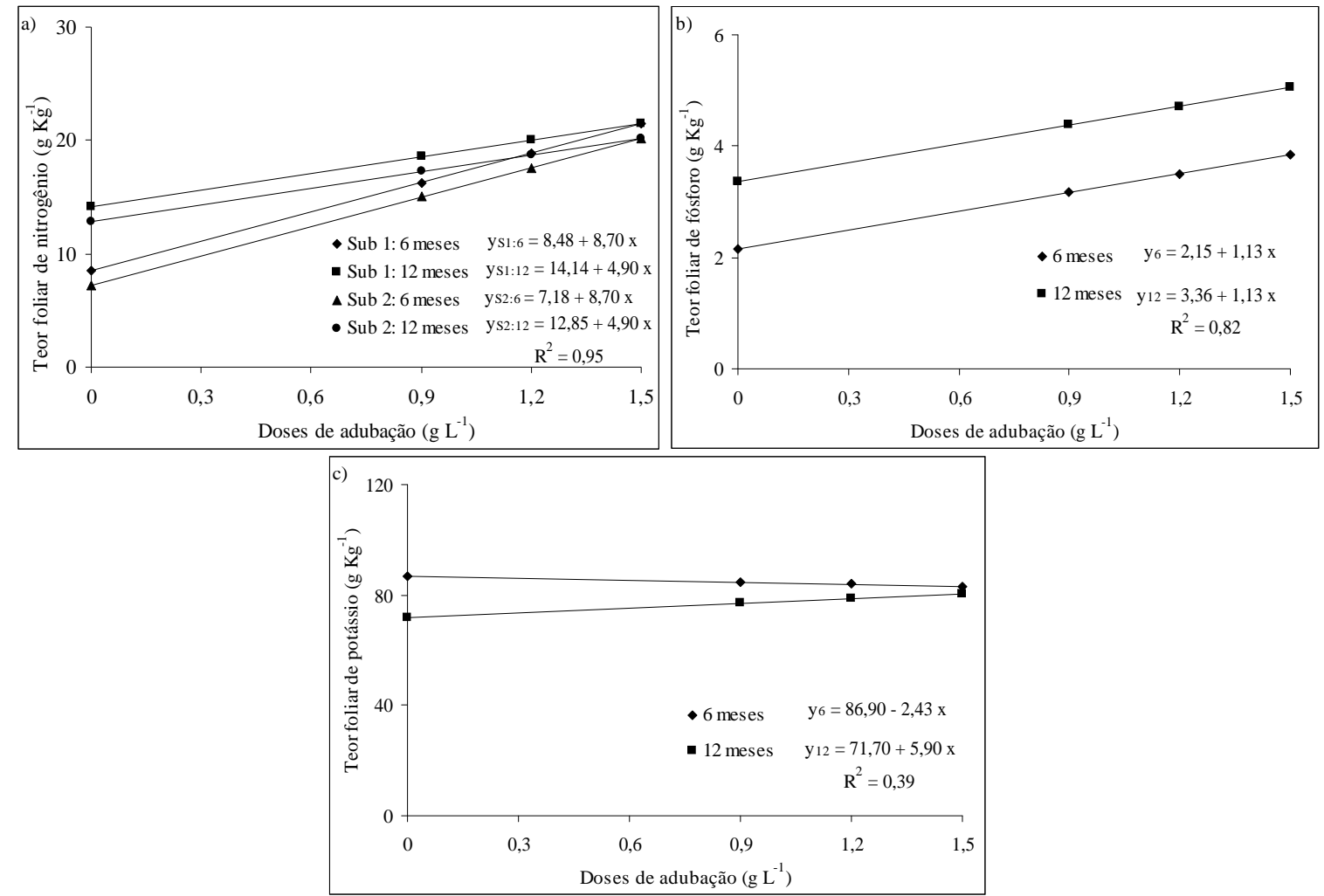

Figura 2 - Plantas de Phalaenopsis RJ 343 cultivadas em substrato com fibra de coco industrializada (Sub1) e não industrializada (Sub2) sob diferentes doses de adubação, aos seis e 12 meses de cultivo: a) teor foliar de nitrogênio, b) teor foliar de fósforo e c) teor foliar de potássio. 
para os teores foliares de $\mathrm{P}$ houve interação significativa entre adubação e substrato (Figura 4c).

Mesmo não havendo interação entre os efeitos do substrato e da adubação sobre a área foliar, a massa seca das folhas e os teores de $\mathrm{N}$ e $\mathrm{K}$ e nem interação entre adubação e época sobre a massa seca das folhas e massa seca das raízes e teores foliares de $\mathrm{P}$ e $\mathrm{K}$, houve interesse de se analisar as variáveis em conjunto. Observaram-se que plantas cultivadas no Sub 1 apresentaram maior área foliar e massa seca das folhas, com maior incremento da massa seca das folhas, aos 12 meses de avaliação (Figura 3b e 3c).

A adubação causou aumento linear nos teores foliares de $\mathrm{N}$ independentemente do substrato, mas houve interação adubação e época de avaliação com os maiores valores observados aos 12 meses para todas as doses de fertilizante mineral aplicadas (Figura 4a). Os teores de K e P tiveram um aumento linear com o aumento da adubação, cujos maiores valores de $\mathrm{K}$ foram observados aos seis meses, e maiores teores de $\mathrm{P}$ foram encontrados aos 12 meses em plantas cultivadas no Sub 1, sem a aplicação de Aminon ${ }^{\circledR}$ (Figura 4b e 4c).

Os valores observados para os teores foliares de $\mathrm{N}$ das plantas nas doses $0,0,9$ e $1,2 \mathrm{~g} \mathrm{~L}^{-1}$ de adubo mineral aos seis meses estão abaixo da faixa adequada citada Jones et al. (1991), enquanto aqueles da dose $1,5 \mathrm{~g} \mathrm{~L}^{-1}$, aos seis meses e todos os valores observados aos 12 meses estão dentro da faixa considerada adequada, bem como os teores de $\mathrm{P}$ de todos os tratamentos. Os teores de $\mathrm{K}$ das plantas de todos os tratamentos estão acima da faixa adequada. Resultados semelhantes aos teores foliares observados de $\mathrm{N}$ e P sem a aplicação de Aminon ${ }^{\circledR}$ foram encontrados por Moreno et al. (2000), enquanto os teores foliares de P com a aplicação de Aminon ${ }^{\circledR}$ são inferiores e os de K são superiores aos encontrados pelo autor.

Para os dois híbridos de Phalaenopsis estudados, RJ 343 e RJ 84-2, houve um acréscimo no número de folhas, área foliar e massa seca das folhas com o aumento das doses de adubo mineral aplicadas, sendo os maiores valores obtidos com a maior dose aplicada $\left(1,5 \mathrm{~g} \mathrm{~L}^{-1}\right)$. Resultados semelhantes foram observados por Wang \& Gregg (1994), que verificaram o aumento no total de folhas, no comprimento e largura da segunda folha completamente expandida e no número de flores e inflorescências, com o incremento da adubação de 0,25 a $1,0 \mathrm{~g} \mathrm{~L}^{-1}$, durante o segundo ano de cultivo. Da mesma forma, AmbergerOchsenbauer (1997), usando de 0,5 a $1,5 \mathrm{~g} \mathrm{~L}^{-1}$ da formulação NPK (16-4-18) em três híbridos de Phalaenopsis, cultivados em vaso $13 \mathrm{com}$ volume de $800 \mathrm{ml}$, verificou um incremento no diâmetro das plantas e no número de flores e botões por planta com o aumento da adubação.

Somente foi observado efeito isolado da época sobre a massa seca das folhas e raízes e sobre os teores foliares de P e K (Tabela 4).

Tabela 2 - Número de folhas (NF), área foliar (AF), área superficial de raízes (AR), massa seca das folhas (MSF), massa seca das raízes (MSR) e massa seca total (MST) e teor foliar de fósforo (P) nas folhas de plantas Phalaenopsis RJ 343 aos seis e 12 meses de cultivo.

\begin{tabular}{cccccccc}
\hline $\begin{array}{c}\text { Meses de } \\
\text { cultivo }\end{array}$ & NF & $\begin{array}{c}\text { AF } \\
\left(\mathrm{cm}^{2}\right)\end{array}$ & $\begin{array}{c}\text { AR } \\
\left(\mathrm{cm}^{2}\right)\end{array}$ & $\begin{array}{c}\text { MSF } \\
(\mathrm{g})\end{array}$ & $\begin{array}{c}\text { MSR } \\
(\mathrm{g})\end{array}$ & $\begin{array}{c}\text { MST } \\
(\mathrm{g})\end{array}$ & $\begin{array}{c}\mathrm{P} \\
\left(\mathrm{g} \mathrm{Kg}^{-1}\right)\end{array}$ \\
\hline 6 & $4,50 \mathrm{a}^{*}$ & $115,20 \mathrm{a}$ & $44,20 \mathrm{a}$ & $0,90 \mathrm{~b}$ & $0,92 \mathrm{~b}$ & $1,98 \mathrm{a}$ & $3,22 \mathrm{~b}$ \\
12 & $4,36 \mathrm{a}$ & $125,07 \mathrm{a}$ & $46,55 \mathrm{a}$ & $1,06 \mathrm{a}$ & $1,07 \mathrm{a}$ & $2,07 \mathrm{a}$ & $4,43 \mathrm{a}$ \\
\hline
\end{tabular}

*Médias seguidas da mesma letra não diferem entre si pelo teste de $\mathrm{F}$, ao nível de 5\% de probabilidade: as letras comparam médias das épocas de avaliação aos 6 e 12 meses de cultivo.

Tabela 3 - Número de folhas (NF), área foliar (AF), área superficial de raízes (AR), massa seca das folhas (MSF), massa seca das raízes (MSR), massa seca total (MST) e teores foliares de nitrogênio (N) e potássio (K) na massa seca das folhas de plantas Phalaenopsis RJ 84-2 cultivadas em substratos com fibra de coco industrializada (Sub 1) e com fibra de coco não industrializada (Sub 2).

\begin{tabular}{ccccccccc}
\hline Substrato & NF & $\begin{array}{c}\text { AF } \\
\left(\mathrm{cm}^{2}\right)\end{array}$ & $\begin{array}{c}\text { ASR } \\
\left(\mathrm{cm}^{2}\right)\end{array}$ & $\begin{array}{c}\text { MSF } \\
(\mathrm{g})\end{array}$ & $\begin{array}{c}\text { MSR } \\
(\mathrm{g})\end{array}$ & $\begin{array}{c}\text { MST } \\
(\mathrm{g})\end{array}$ & $\begin{array}{c}\mathrm{N} \\
\left(\mathrm{g} \mathrm{Kg}^{-1}\right)\end{array}$ & $\begin{array}{c}\mathrm{K} \\
\left(\mathrm{g} \mathrm{Kg}^{-1}\right)\end{array}$ \\
\hline Sub 1 & $3,81 \mathrm{a}^{*}$ & $113,64 \mathrm{a}$ & $45,31 \mathrm{a}$ & $0,89 \mathrm{a}$ & $1,06 \mathrm{a}$ & $2,02 \mathrm{a}$ & $18,69 \mathrm{a}$ & $73,16 \mathrm{a}$ \\
Sub 2 & $3,83 \mathrm{a}$ & $83,38 \mathrm{~b}$ & $30,60 \mathrm{~b}$ & $0,63 \mathrm{~b}$ & $0,65 \mathrm{~b}$ & $1,32 \mathrm{~b}$ & $17,99 \mathrm{a}$ & $70,61 \mathrm{a}$ \\
\hline
\end{tabular}

*Médias seguidas da mesma letra não diferem entre si pelo teste de $\mathrm{F}$, ao nível de $5 \%$ de probabilidade: as letras comparam médias de substratos. 

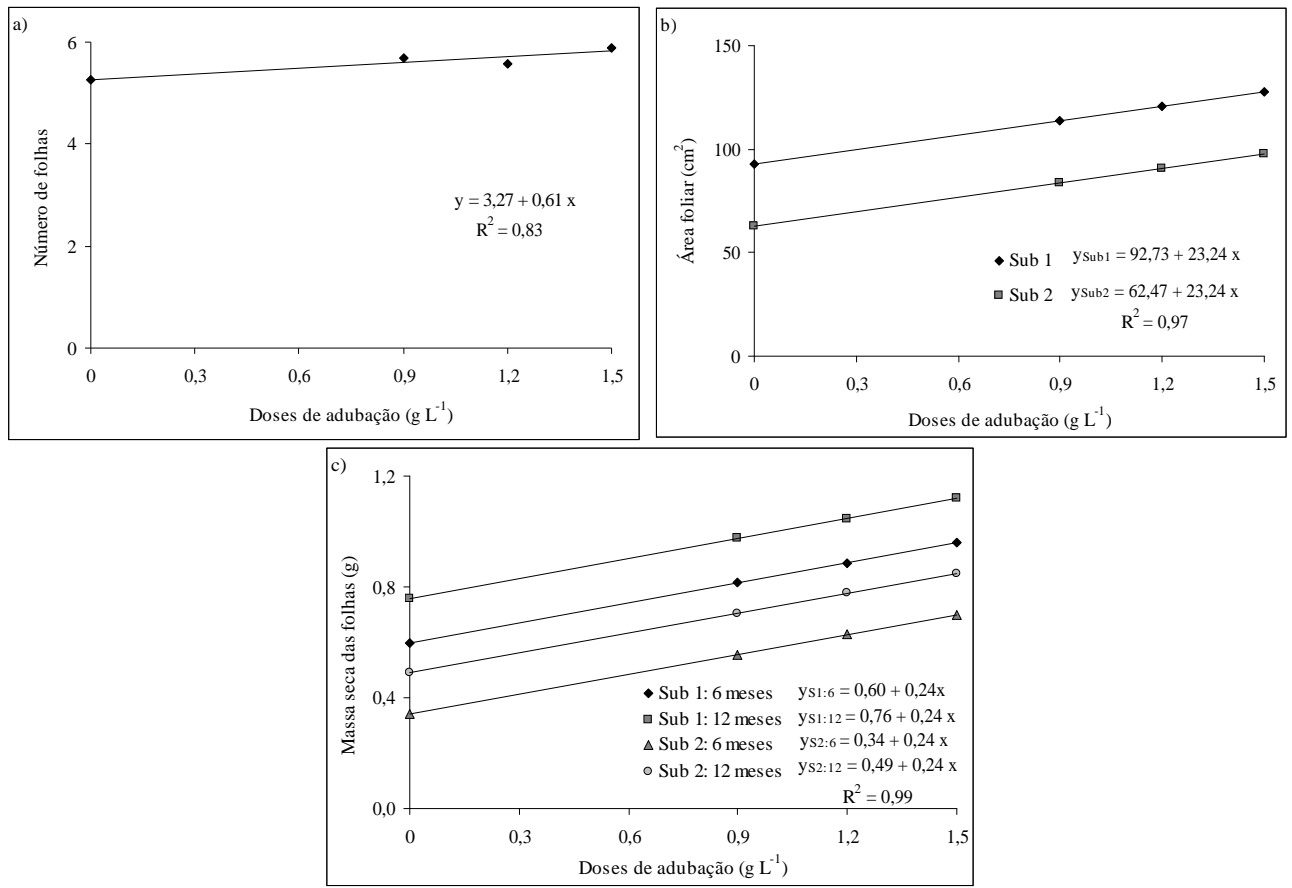

Figura 3 - Plantas de Phalaenopsis RJ 84-2 cultivadas em substrato com fibra de coco industrializada (Sub1) e não industrializada (Sub2) sob diferentes doses de adubação, aos seis e 12 meses de cultivo: a) número de folhas, b) área foliar e c) massa seca das folhas.
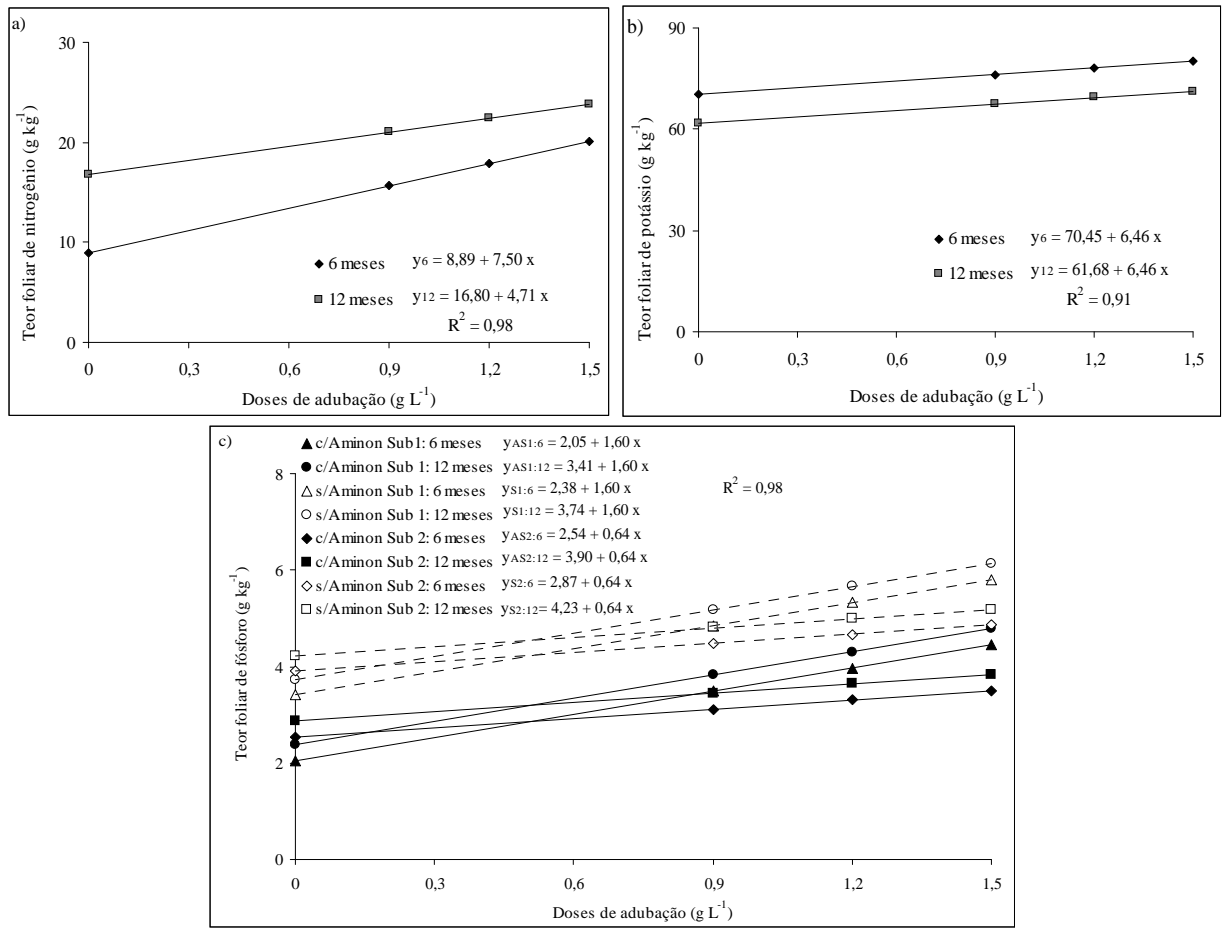

Figura 4 - Plantas de Phalaenopsis RJ 84-2 cultivadas em substratos com fibra de coco industrializada (Sub1) e não industrializada (Sub2) sob diferentes doses de adubação, aos seis e 12 meses de cultivo: a) teor foliar de nitrogênio e b) teor foliar de potássio.

Ciênc. agrotec., Lavras, v. 34, n. 1, p. 11-19, jan./fev., 2010 
Tabela 4 - Número de folhas (NF), área foliar (AF), área superficial de raízes (AR), massa seca das folhas (MSF), massa seca das raízes (MSR) e massa seca total (MST) e teor foliar de fósforo (P) nas folhas de plantas Phalaenopsis RJ 842 aos seis e 12 meses

\begin{tabular}{cccccccccc}
\hline $\begin{array}{c}\text { Meses de } \\
\text { cultivo }\end{array}$ & NF & $\begin{array}{c}\text { AF } \\
\left(\mathrm{cm}^{2}\right)\end{array}$ & $\begin{array}{c}\text { AR } \\
\left(\mathrm{cm}^{2}\right)\end{array}$ & $\begin{array}{c}\text { MSF } \\
(\mathrm{g})\end{array}$ & $\begin{array}{c}\text { MSR } \\
(\mathrm{g})\end{array}$ & $\begin{array}{c}\text { MST } \\
(\mathrm{g})\end{array}$ & $\begin{array}{c}\mathrm{N} \\
\left(\mathrm{g} \mathrm{Kg}^{-1}\right)\end{array}$ & $\begin{array}{c}\mathrm{P} \\
\left(\mathrm{g} \mathrm{Kg}^{-1}\right)\end{array}$ & $\begin{array}{c}\mathrm{K} \\
\left(\mathrm{g} \mathrm{Kg}^{-1}\right)\end{array}$ \\
\hline 6 & $3,81 \mathrm{a}^{*}$ & $92,82 \mathrm{a}$ & $35,75 \mathrm{a}$ & $0,68 \mathrm{~b}$ & $0,75 \mathrm{~b}$ & $1,55 \mathrm{a}$ & $15,63 \mathrm{~b}$ & $3,47 \mathrm{~b}$ & $76,27 \mathrm{a}$ \\
12 & $3,83 \mathrm{a}$ & $104,19 \mathrm{a}$ & $40,15 \mathrm{a}$ & $0,84 \mathrm{a}$ & $0,96 \mathrm{a}$ & $1,79 \mathrm{a}$ & $21,05 \mathrm{a}$ & $4,83 \mathrm{a}$ & $67,50 \mathrm{~b}$ \\
\hline
\end{tabular}

*Médias seguidas da mesma letra não diferem entre si pelo teste de F, ao nível de 5\% de probabilidade: as letras comparam médias das épocas de avaliação aos 6 e 12 meses de cultivo.

Também em plantas de Phalaenopsis, Wang (1996) observou que, ao utilizar seis diferentes formulações de fertilizantes, nas concentrações de 100 a $200 \mathrm{mg} \mathrm{L}^{-1}$ de N, houve aumento no crescimento das plantas, com maior número de folhas e mais largas e com maior área foliar total, nas maiores concentrações aplicadas independentemente da formulação usada.

\section{CONCLUSÕES}

Ambos os substratos podem ser utilizados no cultivo de híbridos de Phalaenopsis, desde que consideradas as exigências particulares de cada material vegetal.

Doses de adubo mineral superiores a $1,5 \mathrm{~g} \mathrm{~L}^{-1}$ podem ser testadas visando determinar a dose máxima de fertilizante, a partir da qual o crescimento seria estabilizado ou diminuído em função da adubação.

O Aminon ${ }^{\circledR}$ não teve efeito sobre o crescimento e desenvolvimento das plantas do Híbrido RJ 343; o maior crescimento das plantas foi observado no Sub 2, sem Aminon $^{\circledR}$, na dose de $1,5 \mathrm{~g} \mathrm{~L}^{-1}$ de adubo mineral aos 12 meses; as faixas de teores foliares de N, P e K observadas para esse híbrido foram, respectivamente: $(16,15-22,23)$, $(3,06-5,21)$ e $(71,88-95,10)$

O Aminon ${ }^{\circledR}$ não teve efeito sobre o crescimento das plantas do Híbrido RJ 84-2; o maior crescimento das plantas foi observado no Sub 1 , sem Aminon ${ }^{\circledR}$, na dose de $1,5 \mathrm{~g} \mathrm{~L}^{-1}$ de adubo mineral aos 12 meses; as faixas de teores foliares de N, P e K para esse híbrido foram, respectivamente: (16,32 $-25,56),(3,49-5,74)$ e $(67,18-86,33)$.

\section{AGRADECIMENTOS}

CNPq - bolsa de Mestrado; FENORTE/TECNORTE - bolsa TNM; Denphal Agrícola Ltda - disponibilização da área, plantas, funcionários, e condições para os experimentos; Setor de Nutrição Mineral de Plantas/CCTA/ UENF- infraestrutura para análise nutricional.

\section{REFERÊNCIAS BIBLIOGRÁFICAS}

AMBERGER-OCHSENBAUER, S. Nutrition and postproduction performance of Phalaenopsis pot plants. Acta Horticulturae, Amsterdam, v.450, p.105-112, 1997.

ASSIS, A.M.; FARIA, R.T.; COLOMBO, L.A.; CARVALHO, J.F.R.P. Utilização de substratos à base de coco no cultivo de Dendrobium nobile Lindl.(Orchidaceae). Acta Scientiarum Agronomy, Maringá, v.27, n.2, p.255-260, abr./jun. 2005.

BRAGA, J.M.; DEFELIPO, B.V. Determinação espectrofotométrica de fósforo em extratos de solos e material vegetal. Revista Ceres, Viçosa, v.21, n.113, p.7385, jan./fev. 1974.

COLOMBO, L.A.; FARIA, R.T.; ASSIS, A.M.; FONSECA, I.C.B. Aclimatização de um híbrido de Cattleya em substratos de origem vegetal sob dois sistemas de irrigação. Acta Scientiarum Agronomy, Maringá, v.27, n.1, p.145-150, jan./mar. 2005.

DEMATTÊ, J.B.I.; DEMATTÊ, M.E.S.P. Estudos hídricos com substratos vegetais para cultivo de orquídeas epífitas. Pesquisa Agropecuária

Brasileira, Brasília, v.31, n.11, p.803-813, nov. 1996.

DEMATTÊ, M.E.S.P.; GRAZIANO, T.T. Growth of Dendrobium nobile Lindl. as related with nutrient concentration in the growing media. Acta Horticulturae, Amsterdam, v.511, p.265-270, 2000.

EUCLIDES, R.F. Sistema para Análises Estatísticas e Genéticas (SAEG). Viçosa, MG: UFV, 1983.

Software. 
FERREIRA, C. A.; PAIVA, P. D. de O.; RODRIGUES, T. M.; RAMOS, D. P.; CARVALHO, J. G. de; PAIVA, P. Desenvouvimento de mudas de bromélia (Neoregelia cruenta (R. Graham) L. B. Smith) cultivadas em diferentes substratos e adubação foliar. Ciênciae Agrotecnologia, Lavras, v. 31, n. 3, p. 666-671, maio/jun., 2007.

GRIESBACH, R.J. A Phalaenopsis in every pot. Orchid Digest, v.59, n.1, p.42-43, 1995.

JACKSON, M.L. Soil chemical analysis. 5.ed. Englewood Cliffs: USA Prentice-Hall, 1965. 498p.

JONES, J.B.; WOLF, B.; MILLS, H.A. Plant analysis handbook: a practical sampling, preparation, analysis, and interpretation guide. Athens: USA Micro-Macro, 1991. 213p.

KIYUNA, I.; ÂNGELO, J.A.; COELHO, P.J. Floricultura: desempenho do comércio exterior em 2006. Instituto de Economia Agrícola, São Paulo, v.1, n.2, fev. 2007. Disponível em: <http://www.iea.sp.gov.br/out/ LerTexto.php? codTexto=8748

MALAVOLTA, E.; VITTI, G.C.; OLIVEIRA, S.A. Avaliação do estado nutricional das plantas: princípios e aplicações. Piracicaba: Associação Brasileira para Pesquisa da Potassa e do Fosfato, 1997. 319p.

MORENO, J.A.E.; ACUÑA, E.A.G.; ROMÁN, A.E.B.; CONTRERAS, D.J.; LÓPEZ, C.T. Fertilización química y biológica de Phalaenopsis (Orchidaceae) en condiciones de invernadero. Terra Volumen, v.18, p.125-131, 2000.

POOLE, H.A.; SEELEY, J.G. Nitrogen, potassium and magnesium nutrition of three orchid genera. Journal of the American Society for Horticultural Science, Madison, v.103, n.4, p.485-488, 1978.
PRIDGEON, A. The illustrated encyclopedic of orchids. Melbourne: Lansdwone, 2001. 304p.

ROCHA, E. L. J.; CARVALHO, A. C. P. P. de; AZEVEDO, B. M. de; MARINHO, A. B.; VIANA, T. V. de A.;

VASCONCELOS, D. V. Aclimatização de mudas micropropagadas de helicônia em ambiente protegido em função do tipo de substrato. Ciênciae Agrotecnologia, Lavras, v. 33, n. 6, p. 1457-1462, nov./dez., 2009.

ROSSIELLO, R.O.P.; ARAÚJO, A.P.; FERNANDES, M.S. Comparação dos métodos fotoelétricos e da interseção da área, comprimento e raio médio radicular. Pesquisa Agropecuária Brasileira, Brasília, v.30, n.5, p.633-638, 1995.

SALVADOR, E.D. Efeito de diferentes substratos no crescimento e desenvolvimento de samambaia matogrossense (Polypodium aureum). 1995. 64f. Dissertação (Mestrado em Fitotecnia)-Universidade Federal de Lavras, Lavras, 1995.

WANG, Y.T. Effects of six fertilizers on vegetative growth and flowering of Phalaenopsis orchids. Scientia Horticulturae, Amsterdam, v.65, p.191-197, 1996.

WANG, Y.T.; GREGG, L.L. Medium and fertilizer affect the performance of Phalaenopsis orchids during two flowering cycles. HortScience, Alexandria, v.29, n.4, p.269-271, 1994.

WANG, Y.T.; LEE, N. A new look for an old crop: potted blooming orchids. Greenhouse Grower, v.12, n.1, p.7980, 1994.

YAMAKAMI, J.K.; FARIA, R.Y.; ASSIS, A.M.; REGOOLIVEIRA, L.V. Cultivo de Cattleya Lindley

(Orchidaceae) em substratos alternativos ao xaxim. Acta Science Agronomy, Madison, v.28, n.4, p.523-526, 2006. 